\title{
LA ARTICULACIÓN DE REMEDIOS EN EL SISTEMA DE LA RESPONSABILIDAD CIVIL DEL CONSUMO
}

[The Articulation of Reparation in the Civil Liability System in Matters Related To Consumption]

\author{
Francisca María Barrientos Camus* \\ Universidad Diego Portales, Santiago, Chile
}

\begin{abstract}
RESUMEN
Este trabajo examina los derechos o remedios que emanan de la garantía legal de la ley de consumo, en función de determinar la forma que ellos se coordinan en beneficio del consumidor. Para ello, se hace preciso estudiar la naturaleza de la responsabilidad civil del proveedor. Se postula la existencia de cinco derechos o acciones irrenunciables para el consumidor: la reparación, la sustitución, la rebaja del precio, la resolución del contrato y la indemnización de perjuicios, que operan a través de un régimen de compatibilidad alternativa y acumulativa
\end{abstract}

\section{Palabras Clave}

Consumo - Responsabilidad civil Garantía legal - Remedios.

\begin{abstract}
This work examines the rights or reparations of the legal guarantees of the law on consumption in order to determine the way in which they coordinate to benefit the consumer. For this, it is necessary to study the nature of civil liability of the supplier. Five inalienable consumer rights or actions are proposed: repair, substitution, price discount, termination of the contract and compensation for damage; they all operate by way of a regime of alternative and accumulative compatibility.

\section{KEYWORDS}

Consumption - Civil liability - Legal guarantees - Rights.
\end{abstract}

RECIBIDO el 16 de enero y ACEPTADo el 2 de mayo de 2014

* Licenciada en Derecho, magíster en Derecho Privado y doctora en Derecho. Profesora de Derecho Civil en la Universidad Diego Portales, investigadora de la Fundación Fernando Fueyo Laneri. Dirección postal: República 112, $2^{\text {do }}$ piso, Santiago, Chile. Correo electrónico: francisca.barrientos@mail.udp.cl. Este trabajo se enmarca en el Proyecto Fondecyt Regular No 1120548 "El tratamiento de las entregas defectuosas en el Derecho chileno: hacia una noción de incumplimiento amplia y unitaria”, y en el Proyecto redes cooperación internacional, REDES 130097, Concurso de apoyo a la formación de redes internacionales, Conicyt. 


\section{INTRODUCCIÓN}

En la Ley No 19.496: Sobre protección de los derechos de los consumidores [= LPDC.], de 1997, no se encuentran reglas especiales que disciplinen el contrato de compraventa celebrado con los consumidores. Sólo se verifica la existencia de una normativa tuitiva a favor del consumidor, que tiene por objeto regular los deberes de información [artículo 3 letra b)], el derecho a retracto (artículo 3 bis y ter), la contratación electrónica (artículo 12-A), el sistema de control de las condiciones generales de la contratación (artículos 16 y 17), la publicidad falsa y engañosa (artículo 28), las promociones y ofertas (artículo 35 ss.), los deberes precontractuales y de información en materia de cobranza extrajudicial (artículo 37 ss.), la indemnización y multa por infracción a los deberes de seguridad de los productos y servicios de consumo masivo (artículo 47), los deberes precontractuales de información mediante la inserción de normas financieras (artículo 17-A ss.), entre otras.

$\mathrm{Si}$ bien, la ley es una norma general y supletoria de las leyes especiales (artículo 2 bis), no hay que olvidar que no prescribe los requisitos, derechos, obligaciones y efectos de los contratos. En este sentido, el derecho común continúa estando en las reglas contenidas en el Código Civil, que será la norma integradora y supletoria de las normas irrenunciables de la ley de consumo.

Esto quiere decir que en las normas de la LPDC. no existen normas generales que reglamenten el contrato de compraventa.

Si bien, el párrafo $5^{\circ}$ del título $2^{\circ}$ de la ley, denominado: "Responsabilidad por incumplimiento", contiene una serie de instituciones diversas, incluso de índole infraccional como el artículo 23, tan sólo en tres disposiciones se ha regulado la responsabilidad civil del proveedor.

El sistema de protección civil del consumidor se manifiesta en la regulación de la denominada garantía legal, contenida en los artículos 19, 20 y 21 LPDC. En estas normas, sólo se regula la inejecución de la obligación de entrega de la cosa y sus consecuencias jurídicas.

Los artículos 19, 20 y 21 disciplinan el sistema de incumplimiento de la entrega en las ventas con consumidores. Y en estas disposiciones, no se constata de forma expresa la existencia de una obligación de entrega de la cosa. Más bien, se regularía un supuesto de hecho amplio sobre entregas defectuosas, de forma dispersa.

Si se pretende agruparlo se dirá que contiene las faltas de especificaciones [artículo 20 letras a), b), d) y e)], las anomalías de calidad [artículo 20 letras c), e) y f)], las anomalías de cantidad de las cosas (artículo 19) y las declaraciones publicitarias que se integran al contrato [artículo 20 letra c)].

Con todo, detrás de estas normas sería posible concebir un deber especial de prestación del proveedor, diverso del reglamentado en el Código Civil a propósito del saneamiento de los vicios redhibitorios.

Esto se traduciría en la existencia de una obligación de parte del pro- 
veedor no regulada expresamente, que ordena una determinada forma de cumplir la entrega de las cosas de consumo masivo, diverso del codificado que las fragmenta en dos. Las obligaciones, señala el Código Civil, se reducen en general a dos: la entrega o tradición y el saneamiento de la cosa vendida (artículo 1824 CC.).

Esta obligación del proveedor contiene un supuesto amplio que se conoce en el modelo de modernización de obligaciones como "garantía de conformidad".

Y si esto es así, sería posible concebir en las ventas con consumidores un modelo unitario de incumplimiento que contemplaría un sistema articulado de remedios disponibles a favor del consumidor. Este es el objeto de estudio de este artículo.

En la primera parte, se examinarán las bases necesarias para configurar este sistema de responsabilidad por cumplimiento defectuoso de la entrega de la cosa de consumo masivo, luego una descripción de los remedios o derechos que ofrece la garantía legal, y por último, la forma en que operarían estos derechos, a través de una fórmula de compatibilidad alternativa y acumulativa, a favor del consumidor.

\section{LAS BASES PARA CONSTRUIR UN SISTEMA UNITARIO DE RESPONSABILIDAD CIVIL DE CONSUMO}

La conformidad (o la falta de conformidad), es un concepto anglosajón introducido en los sistemas continentales a partir de la unificación europea del Derecho de contratos y obligaciones ${ }^{1}$. Implica congruencia entre la cosa entregada y las pretensiones del comprador.

Si se vincula a la idea del objeto, conformidad implica, por tanto, correspondencia de la cosa entregada con el modelo que exige el contrato ${ }^{2}$. En general, conformidad significa que la cosa entregada por el vendedor ha de adecuarse a las exigencias cualitativas y cuantitativas que el contrato le impo$\mathrm{ne}^{3}$, las características pactadas y lo efectivamente entregado al consumidor ${ }^{4}$.

${ }^{1}$ Por todos, véase: Zimmermann, Reinard, El carácter europeo del Derecho inglés. Relaciones históricas entre el "civil law" y "common law" en El mismo, Estudios de Derecho privado europeo (traducción de A. Vaquer, Madrid, Civitas, 2000), pp. 161-228.

${ }^{2}$ Morales Moreno, Antonio Manuel, La conformidad de la cosa vendida según la Directiva 1999/44/CE, en La modernización del derecho de las obligaciones (Madrid, Thomson Civitas, 2006), p. 169.

${ }^{3}$ Morales Moreno, Antonio Manuel, Adaptación del Código Civil al derecho europeo: la compraventa, en La modernización del derecho de las obligaciones (Madrid, Thomson Civitas, 2006), p. 96.

${ }^{4}$ Castilla Barea, Margarita, La determinación de la "falta de conformidad" del bien con el contrato a tenor del art. 2 de la Directiva 1999/44/C.E., del Parlamento Europeo y del Consejo, de 25 de mayo, sobre determinados aspectos de la venta y las garantías 
Ya se ha dicho que la obligación de entrega de la cosa en la LPDC. no está regulada de forma expresa.

Por ese motivo, sería posible reconstruirla a contrario sensu, de la misma forma que se hizo en la Convención de las Naciones Unidas sobre los contratos de compraventa internacional de mercaderias, que forma parte del derecho interno de nuestro país desde el año 1990.

Así lo señala Antonio Morales ${ }^{5}$ que describe que esta normativa exige en primer término que las mercaderías sean conformes al contrato (artículo $35,1)$ y en el párrafo segundo indica los criterios que se han de utilizar para determinar la conformidad, mediante la regulación de la falta de conformidad (artículo 35,2) .

De los artículos 19 y 20 de la ley sería posible inferir que la obligación de entrega supone que la cosa debe ser adecuada (o conforme) en cantidad, calidad, tipo, seguridad, envase o embalaje, entrega diversa a la pactada y declaraciones publicitarias.

Incluso, desde otra perspectiva se podría señalar que nuestra doctrina civil

de los bienes de consumo, en Anuario de la Facultad de Derecho de la Universidad de Extremadura, 21 (2003), p. 282.

${ }^{5}$ Morales Moreno, Antonio Manuel, La compraventa internacional de mercaderías. Comentario de la "Convención de Viena" (Madrid, Thomson Civitas, 1997), p. 289; en Chile: Vidal Olivares, Álvaro, La protección del comprador. Régimen de la Convención de Viena y su contraste con el Código Civil (Valparaíso, Ediciones Universitarias de Valparaíso, 2006), pp. 51 ss.

${ }^{6}$ Esta es la misma técnica empleada en algunos instrumentos de "softlaw". En los "Principios Unidroit" no se conoce la expresión conformidad, ni existe una regulación concreta respecto de ella. Se infiere su existencia a contrario sensu, a partir de la regulación general del incumplimiento contractual. En su texto, en el artículo 7,1,1 hace mención a la falta de ejecución por una parte de alguna de sus obligaciones contractuales, incluyendo el cumplimiento defectuoso o el cumplimiento tardío. Más adelante, los PECL. tampoco se refieren a la conformidad, en el artículo 8:103 definen el incumplimiento esencial haciendo alusión a la causa del contrato o la privación sustancial de la parte perjudicada de lo que legítimamente podía esperar del contrato, o el incumplimiento sea intencionado. Por su parte el Borrador para un Marco Común de Referencia de 2009, lo regula en libro I, artículo 1:102 de forma más objetiva, como cualquier desviación ("failure") en el cumplimiento de la obligación, se encuentre o no excusada, e incluye el cumplimiento tardío y cualquier otro cumplimiento que no sea acorde a los términos que regula la obligación. Los Acquis principles II (versión 2009) regulan en su artículo 8:101 la definición de incumplimiento, como cualquier cumplimiento insuficiente de una obligación, incluido el cumplimiento moroso, el cumplimiento defectuoso y la infracción del deber de cooperar con el fin de procurar la plena eficacia de una obligación. 
de la mano de Barros ${ }^{7}$, Vidal $^{8}$, Pizarro ${ }^{9}$, Peñailillo ${ }^{10}$, de la Maza ${ }^{11}$, Brantt $^{12}$

${ }^{7}$ BARros Bourie, Enrique, El contrato y el hecho que causa daño como antecedentes de la responsabilidad, en Pizarro Wilson, Carlos (editor), Estudios de Derecho Civil IV (Santiago, LegalPublishing, 2009), pp. 297-313; BArros Bourie, Enrique, Finalidad y alcance de las acciones y remedios contractuales, en GUZMÁn BRITO, Alejandro (editor científico), Estudios de Derecho Civil III (Santiago, LegalPublishing, 2008), pp. 403-428; BARRos BourIe, Enrique, La diferencia entre "estar obligado" y "ser responsable" en el Derecho de los contratos, en Corral, Hernán - RodrígueZ, María Sara (editores), Estudios de Derecho Civil II (Santiago, LexisNexis, 2006), pp. 721-752.

${ }^{8}$ Vidal Olivares, Álvaro, La indemnización de daños y la opción del acreedor frente al incumplimiento, en Figueroa YÁnez, Gonzalo (editor), Estudios de Derecho Civil VI (Santiago, AbeledoPerrot - LegalPublishing, 2011), pp. 763-780; VIDAL OlivARES, Álvaro, La noción de incumplimiento esencial en el "Código Civil", en Revista de Derecho de la Pontificia Universidad Católica de Valparaiso, 32 (2009), pp. 221-258; Vidal Olivares, Álvaro, El incumplimiento resolutorio en el “Código Civil”, en PizaRro Wilson, Carlos (editor), Estudios de Derecho Civil IV (Santiago, LegalPublishing, 2009), pp. 347-368; VIDAL Olivares, Álvaro, El incumplimiento de obligaciones con objeto fungible y los remedios del acreedor afectado. Una relectura de las disposiciones del "Código Civil" sobre incumplimiento, en Guzmán BRITo, Alejandro (editor científico), El Código Civil de Chile (1855-2005) (Santiago, LexisNexis, 2007), pp. 495-550; Vidal Olivares, Álvaro, La pretensión de cumplimiento especifico y su inserción en el sistema de remedios por incumplimiento en el "Código Civil", en Corral, Hernán Rodríguez, María Sara (editores), Estudios de Derecho Civil II (Santiago, LexisNexis, 2007), pp. 517-538; Vidal Olivares, Álvaro, Cumplimiento e incumplimiento contractual en el "Código Civil". Una perspectiva más realista, en Revista Chilena de Derecho, 34 (Santiago, 2009) 1, pp. 41-59; Vidal Olivares, Álvaro, El incumplimiento contractual y los remedios de que dispone el acreedor en la compraventa internacional, en Revista Chilena de Derecho, 33 (Santiago, 2006) 3, pp. 439-477; Vidal Olivares, Álvaro, La protección del comprador. Régimen de la Convención de Viena y su contraste con el Código Civil (Valparaíso, Ediciones Universitarias de Valparaíso, 2006).

${ }^{9}$ Pizarro Wilson, Carlos, Hacia un sistema de remedios al incumplimiento contractual, en Guzmán Brito, Alejandro (editor científico), Estudios de Derecho Civil III (Santiago, LegalPublishing, 2008), pp. 395-402; Pizarro Wilson, Carlos, La culpa como elemento constitutivo del incumplimiento en las obligaciones de medio o de diligencia, en Revista de Derecho de la Pontificia Universidad Católica de Valparaiso, 31 (Valparaíso, 2008), pp. 255-265; Pizarro Wilson, Carlos, La responsabilidad contractual en Derecho chileno, en Pizarro Wilson, Carlos - Vidal Olivares, Álvaro Incumplimiento contractual, resolución e indemnización de daños (Bogotá, Universidad del Rosario, 2010), pp. 299-312.

${ }^{10}$ Peñallillo Arévalo, Daniel, Responsabilidad contractual objetiva, en Pizarro Wilson, Carlos (editor), Estudios de Derecho Civil IV (Santiago, LegalPublishing, 2009), pp. 331-346.

${ }^{11}$ De la Maza Gazmuri, Ínigo, El concurso entre el error con trascendencia anulatoria y el incumplimiento resolutorio, en de la Maza, Íñigo (coordinador), Cuadernos de Análisis Jurídico, VII: Incumplimiento contractual. Nuevas perspectivas. (Santiago, Universidad Diego Portales, 2011), pp. 213-235; De la Maza Gazmuri, Íñigo, El régimen de los cumplimientos defectuosos en la compraventa, en Revista Chilena de Derecho, 39 (Santiago, 2011) 3, pp. 629-663.

${ }^{12}$ Brantt Zumarán, María Graciela, La prueba del cumplimiento imperfecto en 
y Mejías ${ }^{13}$, entre otros, siguiendo las directrices de una parte de la doctrina española ${ }^{14}$, ha hecho esfuerzos para reconstruir este nuevo modelo modernizador de las obligaciones, a partir de las disposiciones del Código Civil, sin que sea necesaria una reforma legislativa. Esto no sería necesario en sede de consumidores, pues las mismas disposiciones de la ley, a contrario sensu, contemplarían este modelo.

De este modo, sería posible afirmar la existencia de una obligación de entrega conforme en las ventas con consumidores, como antecedente de la eventual reparación, sustitución, rebaja del precio o resolución del contrato con la indemnización de perjuicios que emana de la responsabilidad civil del consumo, denominada garantía legal o derecho de opción.

Dicho esto, ahora conviene destacar algunas directrices del modelo propuesto, que sirven para justificar la introducción de la obligación de entrega conforme en las ventas de consumo, como el propósito práctico, la

las obligaciones de medios y de resultado, en ElORRIAGA, Fabián (coordinador), Estudios de Derecho Civil VII (Santiago, Thomson Reuters - AbeledoPerrot, 2012), pp. 495-510; Brantt Zumarán, María Graciela, El caso fortuito: concepto y función como limite de la responsabilidad contractual, en DE LA MAZA, Íñigo (coordinador), Cuadernos de Análisis Jurídico, VII: Incumplimiento contractual. Nuevas perspectivas (Santiago, Universidad Diego Portales, 2011), pp. 47-82; Brantt Zumarán, María Graciela, El caso fortuito y su incidencia en el derecho de la responsabilidad contractual. Concepto y función del caso fortuito en el "Código Civil" chileno (Santiago, LegalPublishing, 2010).

${ }^{13}$ Mejías Alonzo, Claudia, El incumplimiento contractual y sus modalidades, en Varas, Juan Andrés - Turner, Susan (editores), Estudios de Derecho Civil II (Santiago, Editorial LexisNexis, 2005), pp. 459-478; MEjÍAs Alonzo, Claudia, El incumplimiento resolutorio en la jurisprudencia nacional, en FigueroA YáÑEZ, Gonzalo (editor), Estudios de Derecho Civil VI (Santiago, AbeledoPerrot - Legal Publishing, 2011), pp. 751-762; Mejías Alonzo, Claudia, El incumplimiento resolutorio en el Código Civil (Santiago, AbeledoPerrot - Legal Publishing, 2011).

${ }^{14}$ Entre otros, véanse: DíEZ-PICAzo y PonCe De León, Luis, La compraventa internacional de mercaderías. Comentario de la Convención de Viena (Madrid, Civitas, 1997); Díez-Picazo y Ponce de León, Luis, Reforma de los Códigos y Derecho Europeo, en Anuario de Derecho Civil, 56 (Madrid, 2003) 4, pp. 1565-1574; Morales Moreno, Antonio Manuel, La modernización del Derecho de las obligaciones (Navarra, Thomson Civitas, 2006); Fenoy Picón, Nieves, Falta de conformidad e incumplimiento en la compraventa: evolución del ordenamiento español (Madrid, Centro de Estudios Registrales, 1996); Fenoy Picón, Nieves, El sistema de protección del comprador (Madrid, Centro de Estudios Registrales, 2006); SAN Miguel Pradera, Lis Paula, Resolución del contrato por incumplimiento y modalidades de ejercicio (Madrid, Colegio de Registradores de la Propiedad y Mercantiles de España, 2006); Pantaleón Prieto, Ángel Fernando, El sistema de responsabilidad contractual: (materiales para un debate), en Anuario de Derecho Civil, 44 (Madrid, 1991) 3, pp. 1019-1092; Pantaleón PrieTO, Ángel Fernando, Las nuevas bases de la responsabilidad contractual, en Anuario de Derecho Civil, 46 (Madrid, 1993) 4, pp. 1719-1746. 
noción realista del contrato, la satisfacción del interés del consumidor y la responsabilidad objetivada del proveedor.

\section{El propósito práctico.}

En primer lugar, hay que señalar que el consumidor y el proveedor tienen un propósito práctico para celebrar el contrato. El contrato es un mecanismo de distribución de riesgos, su fin es que cada parte proporcione a la otra un beneficio o que actué de una manera conducente a procurarle esta ventaja o beneficio $^{15}$. Las partes que celebran compraventas pretenden coordinar sus intereses para comprar y vender.

Si se atiende, entonces, a ese propósito práctico será posible identificar su interés para contratar. En la idea de Federico De Castro, el negocio jurídico nace con el acuerdo de voluntades para conseguir un resultado. Se trata, entonces, de "[...] la declaración o acuerdo de voluntades, con los que los particulares se proponen conseguir un resultado, que el Derecho estima digno de especial tutela, sea en base sólo a dicha declaración de voluntad, sea completado con otros hechos o actos" ${ }^{16}$. Conectado con lo anterior, Antonio Morales ${ }^{17}$ sugirió que era necesario atender a la idea de un resultado, “[...] la importancia del resultado que se pretende alcanzar a través del negocio trasciende al negocio mismo, entendiendo como real, y se proyecta sobre la realidad, sobre la situación concreta que cada negocio configura" ${ }^{18}$.

Con anterioridad, Emilio Betti ${ }^{19}$, estimaba que el fin de la relación jurídica era la tutela y satisfacción del interés del acreedor a la cooperación del deudor. Interés económico social que se manifiesta en el interés de una prestación ajena, que distingue un momento subjetivo (conducta de cooperación requerida al deudor) y un momento objetivo (utilidad de la prestación para el acreedor).

\section{La noción realista del contrato.}

Así, todo esto indica que detrás hay una noción realista del contrato. Desde esta perspectiva el contrato no es sólo un instrumento de creación de derechos y obligaciones, como se define en nuestro Código Civil centrado en

${ }^{15}$ Barros Bourie, Enrique, cit. (n. 7) Finalidady alcance, p. 297.

${ }^{16}$ De Castro y Bravo, Federico, El negocio jurídico (Madrid, Civitas, 1985), p. 33.

${ }^{17}$ Morales Moreno, Antonio Manuel, El "propósito práctico" y la idea de negocio jurídico en Federico De Castro, en La modernización del Derecho de las obligaciones (Madrid, Thomson Civitas, 2006), p. 330.

${ }^{18}$ IBíD.

${ }^{19}$ BetTi, Emilio, Teoría general de las obligaciones (traducción de José Luis de los Mozos, Madrid, Editorial Revista de Derecho Privado, 1969), pp. 6, 37, 54 y 55. 
la noción de obligación (artículo 1438), sino que se considera un mecanismo para regular, organizar y alcanzar la satisfacción delos intereses de las partes.

La función económica del contrato y el interés se encuentra "[...] dibujado a partir del fin o propósito práctico que determinó su celebración y que se alcanza con la fiel y oportuna realización del programa de prestación" ${ }^{20}$, que equivaldría a la causa ocasional del artículo 1467 CC.

Aplicando lo anterior, el proveedor no sólo estaría obligado a entregar la cosa y sanearla (artículo 1824 CC.), sino que además, se obligaría a entregarla conforme las expectativas del comprador, que incluyen la existencia de vicios ocultos, anomalías de cantidad, de calidad, aliud pro alio, entre otras.

\section{La satisfacción del interés del consumidor.}

Relacionado con esto con lo anterior, es posible concebir que en las ventas de cosas masivas el proveedor debe entregar la cosa integrando el interés del consumidor al contratar.

Por ello es exigible no sólo la calidad pactada o la que se espera de la cosa, sino que también la cantidad, las especificaciones concretas formuladas al proveedor o que la ley señala, e incluso ciertas declaraciones publicitarias hechas por terceros ajenos al contrato.

De este modo, el proveedor cumple cuando entrega lo esperado, prometido, o señalado en la publicidad por el proveedor, sin que pueda excusarse en la diligencia para eximirse de responsabilidad. Como lo sostiene Antonio Morale $^{21}$, la relación obligatoria puede implicar la garantía de un resultado para el acreedor, que pesa sobre el deudor. O como lo sugiere Álvaro Vidal: "[E]l acento está en la protección del interés del acreedor y es el deudor quien debe realizar lo suficiente (satisfacere), y sólo si lo realiza se libera del vínculo que nace del contrato. Según esta idea la solutio sería una consecuencia inmediata de la satisfactio y ella presupone la satisfacción del interés del acreedor conforme el contrato" 22 .

En definitiva, los intereses económicos de las partes importan en la contratación con consumidores. El propósito práctico forma parte del contrato, obliga al vendedor en miras ala satisfacción de los intereses del acreedor.

\section{La responsabilidad civil objetivada.}

Por último, además hay que agregar que el régimen contemplado en la

${ }^{20}$ Vidal Olivares, A., El incumplimiento, cit. (n. 8), p. 508.

${ }^{21}$ Morales Moreno, Antonio Manuel, Evolución del concepto de obligación en el derecho español, en La modernización del Derecho de las obligaciones (Madrid, Thomson - Civitas, 2006) p. 19.

${ }^{22}$ Vidal Olivares, A., El incumplimiento, cit. (n. 8), p. 508. 
garantía legal sería de corte objetivo, que prescinde de la culpa para imputar responsabilidad al proveedor.

Idea, que se ha venido forjando en la doctrina civil para el sistema de incumplimiento general, primero al despejar la culpa del incumplimiento, y luego acercándolo a las obligaciones de resultado.

En efecto, la doctrina tradicional consideraba que la culpa "era un fantasma que rondaba el incumplimiento" 23 . Este elemento era necesario para la puesta en marcha de todos efectos. Si el incumplimiento no era imputable, no se desplegaban los efectos de las obligaciones.

Ahora, esta forma de entender el régimen de responsabilidad ha ido cambiando. Ya no sería posible acoger la idea de una sanción o un castigo, porque no se exige una situación antijurídica o una actividad culpable del deudor para dar lugar a la reparación, sustitución, rebaja del precio o resolución del contrato, al parecer sí para otorgar la indemnización de perjuicios.

Por la regulación de los artículos 19 y 20 LPDC., que no mencionan la diligencia o negligencia del proveedor, el contenido de la relación obligatoria sería la entrega de una cosa bajo las reglas de la responsabilidad objetiva que atiende las expectativas del consumidor.

Para sostener que la garantía legal es objetiva, también adquiere importancia la distinción entre obligaciones de medio y de resultado. La obligación de entrega se erige como una obligación de resultado, no de medios. Si se toma la idea de Enrique Barros ${ }^{24}$, que planteó que el régimen de la responsabilidad civil contractual se ha ido objetivando a través de la introducción de las obligaciones de resultado, sería posible construir una especie de culpa infraccional que garantice la conformidad del consumidor. Lo que se complementa con la opinión de Álvaro Vidal ${ }^{25}$ y Carlos Pizarro ${ }^{26}$, que sugieren que en esta clase de obligaciones existe una culpa promotora, no integradora de la obligación. Es decir, en las obligaciones de resultado se exige tan sólo una diligencia mínima para desplegar la actividad necesaria para dar curso a la ejecución (diligencia promotora), que difiere con las obligaciones de medios, en que la diligencia se integra a la prestación misma (diligencia integradora).

La adopción de una culpa promotora tiene importancia para determinar

${ }^{23}$ En la frase de Vidal Olivares, A., El incumplimiento, cit. (n.10), p. 503; Fueyo LANERI, Fernando, Cumplimiento e incumplimiento de las obligaciones (Santiago, Editorial Jurídica de Chile, 2004), p. 256; Abeliuk Manasevich, René, Las obligaciones (5a edición actualizada, Santiago, Editorial Jurídica de Chile, 2010), p. 817.

${ }^{24}$ Barros Bourie, E., Finalidad y alcance, cit. (n. 7), p. 427; Barros Bourie, E., El contrato, cit. (n. 7), p. 305.

${ }^{25}$ Vidal Olivares, A., Cumplimiento, cit. (n. 8), pp. 41-59.

${ }^{26}$ Pizarro Wilson, C., La culpa, cit. (n. 9), pp. 255-265. 
la existencia del caso fortuito como límite de la responsabilidad contractual ${ }^{27}$, o para entender la regla del artículo 1547 CC., que podría estar referida únicamente a las obligaciones de medios ${ }^{28}$, o bien a ambas ${ }^{29}$. Una noción similar planteaba tiempo atrás Jorge Baraona ${ }^{30}$ y en la actualidad Daniel Peñailillo ${ }^{31}$, que entienden la responsabilidad contractual en clave objetiva, al despejar la estimatio rei del id quod interest de la indemnización de perjuicios. De modo que el cumplimiento en naturaleza, por equivalencia y la indemnización serían conceptos diversos, que no requerirían negligencia en el deudor.

Así las cosas, el proveedor responde porque se compromete a entregar una cosa conforme a lo esperado por el consumidor, lo que asume como un resultado.

Esa es la perspectiva que hay que asumir en el ámbito del consumo. No hay que cimentar las bases de la responsabilidad (en sentido amplio) en atención a la conducta del proveedor deudor, sino que al resultado esperado por el consumidor. Por ello, se dice que el deudor se obliga a una garantía de resultado, cual es la satisfacción de las expectativas del acreedor. No puede eximirse alegando ausencia de culpa. Si hay una disconformidad con la cosa debe repararla, sustituirla, rebajar el precio o resolver el contrato, a petición del consumidor sin que pueda excusarse en la diligencia empleada.

Desde otra perspectiva, y con anterioridad Hernán Corral ${ }^{32}$ afirmaba el carácter objetivo de la garantía legal, porque lo asimilaba al régimen de las acciones edilicias, en que no se duda de la prescindencia de culpa. En su concepto, el expendedor no podría excusarse ni aun cuando alegue que el deterioro se debió a caso fortuito, como sería un régimen estricto de responsabilidad. Sin embargo, con posterioridad, sostuvo que sólo podrá alegarse fuerza mayor o caso fortuito cuando éstos quiebren el nexo de causalidad ${ }^{33}$.

${ }^{27}$ En el sentido que sólo excluye uno de los mecanismos previstos por el legislador a favor del acreedor insatisfecho: la indemnización de perjuicios, sin que extinga las demás obligaciones BrANTT, M. G., El caso fortuito: concepto y función, cit. (n. 12), p. 79-81, y con anterioridad, BRANTT, M. G., El caso fortuito y su incidencia, cit. (n. 14).

${ }^{28}$ Pizarro Wilson, C, La culpa, cit. (n. 9), pp. 255-265.

${ }^{29}$ Brantt Zumarán, M. G., La prueba, cit. (n. 12), pp. 499-501.

${ }^{30}$ Baraona Gonzalez, Jorge, Responsabilidad contractual y factores de imputación de daños: apuntes para una relectura en clave objetiva, en Revista Chilena de Derecho, 24 (Santiago, 1996) 1, pp. 151-177.

${ }^{31}$ Peñallillo Arévalo, D., cit. (n. 12), pp. 332-335.

${ }^{32}$ Corral Talciani, Hernán, Ley de protección al consumidor y responsabilidad civil, en Corral, Hernán (editor), Cuadernos de Extensión Jurídica, III: Derecho del consumo y protección al consumidor. Estudios sobre la Ley $N^{\circ} 19.496$ y las principales tendencias extranjeras (Santiago, Ediciones Universidad de los Andes, N³, 1999), p. 178.

${ }^{33}$ Corral Talciani, Hernán, La responsabilidad por incumplimiento y por productos peligrosos en la ley de protección de los derechos de los consumidores, en BARAONA, 
Dicho esto, ahora corresponde examinar cuáles son los derechos o remedios que emanan de la garantía legal.

\section{LOS REMEDIOS DISPONIBLES PARA EL CONSUMIDOR}

Y lo primero que conviene señalar es que los remedios que nacen del cumplimiento defectuoso de la obligación de entrega del proveedor no cuentan con una regulación sistemática.

Pese a que se ha defendido en las líneas anteriores la existencia de una obligación unitaria y amplia, similar a la entrega conforme del sistema de la "Convención de Viena" sobre venta de mercaderías internacionales, instrumento que marca un nuevo paradigma en el derecho de contratos y obligaciones, al ser más amplia que el régimen codificado decimonónico, hay que señalar que el sistema de remedios en las ventas con consumidores se encontraría más o menos articulado. No se sabe la razón, pero es posible distinguir los derechos disponibles para el consumidor para las anomalías de cantidad y todas las demás (faltas de especificaciones, anomalías de calidad y declaraciones publicitarias).

En efecto, el artículo 19, que ampara los vicios de cantidad, consagra el derecho a la sustitución, la rebaja del precio y la bonificación, que es una especie de sustitución. Por su parte, el artículo 20 contempla la reparación, la sustitución, la resolución y la indemnización de perjuicios.

Estos derechos o remedios se examinarán a continuación ${ }^{34}$.

\section{La reparación.}

Y como se señalaba con anterioridad, la reparación sólo está contemplada en el artículo 20, mas no en el artículo 19, que supone una forma de cumplimiento in natura de la cosa.

No está consagrada en el artículo 19, ya que se trataría de un remedio

Jorge - LAGOs, Osvaldo (editores), Cuadernos de extensión Juridica, XII: La protección de los derechos de los consumidores en Chile. Aspectos sustantivos y procesales luego de la reforma contenida en la Ley $N^{\circ} 19.955$ de 2004 (Santiago, Ediciones Universidad de los Andes, 2006), p. 101.

${ }^{34}$ Se ha tenido a la vista la exposición efectuada por BARrientos CAMUs, Francisca, Comentario al artículo 19 y comentario al artículo 20, en DE LA MAZA, Iñigo Pizarro, Carlos (directores) - BARrientos, Francisca (coordinadora), La protección de los derechos de los consumidores. Comentarios a la ley de protección a los derechos de los consumidores (Santiago, Thomson Reuters), pp. 518-523 y pp. 524-538; y por NASSER Olea, Marcelo, Comentario al artículo 21, en DE la MAZA, Iñigo - Pizarro, Carlos (directores) - BARRIEnTos, Francisca (coordinadora), La protección de los derechos de los consumidores. Comentarios a la ley de protección a los derechos de los consumidores (Santiago, Thomson Reuters), pp. 539-552. 
ineficaz para los vicios cuantitativos. Así lo sugiere Hernán Corral ${ }^{35}$, que explica que en su lugar se otorga el derecho a la bonificación, o sea, la imputación del valor del precio pagado por el bien defectuoso en la compra de otro producto diferente.

La reparación es una medida de corrección o subsanación de la entrega disconforme, que favorece la conservación del contrato. En este sentido, Pilar Martín ${ }^{36}$ lo concibe como una manipulación del producto vendido, la cual tiene por objeto corregir los defectos o las anomalías que el mismo presenta. La Directiva 44/99 del Parlamento Europeo y del Consejo, de 25 de mayo de 1999, sobre determinados aspectos de la venta y las garantías de los bienes de consumo lo considera en términos de "poner el bien de consumo en un estado que sea conforme al contrato de venta" [artículo 1,2 letra f)].

Es un remedio que va más allá de la clásica ejecución en naturaleza. Como lo señala Antonio Morales: "[P]ermite al comprador (acreedor) obtener in natura la satisfacción del interés del acreedor (obtener una cosa conforme al contrato), con independencia de cuál pueda ser, primariamente, el deber de prestación del vendedor. Es una pretensión de cumplimiento configurada a la medida del interés del acreedor, que debe ser satisfecho" ${ }^{37}$.

Esto, repercute de forma directa en la consideración de la vinculación contractual. Como se trata de perseguir un resultado (garantía de resultado), se reconoce de forma expresa la subsanación del cumplimiento defectuoso. No se utiliza la concepción romana que perseguiría una suma pecuniaria por vía indemnizatoria, sino que ahora importa el cumplimiento in natura de la obligación de especie, que no se encuentra regulado en el saneamiento del vicio redhibitorio.

Este derecho supone un reconocimiento al funcionamiento del tráfico de consumo masivo, y constituye una superación de las acciones edilicias del Código Civil.

Por regla general, los consumidores que compran las cosas producidas en masa no pretenden la reducción del precio o resolución del contrato, sino que quieren la subsanación del incumplimiento mediante la reparación de la cosa. Por lo tanto, es eficaz para el consumidor y también para el vendedor. Es útil para los vendedores, toda vez que constituiría una forma de darles una segunda oportunidad ${ }^{38}$, sin acudir al término del contrato.

${ }^{35}$ Corral Talciani, H., Ley de protección al consumidor, cit. (n. 30), p. 172.

${ }^{36}$ Martín Aresti, Pilar, Las garantías de los productos de consumo (Navarra, Aranzadi - Thomson Reuters, 2010) p. 100.

${ }^{37}$ Morales Moreno, Antonio Manuel, El derecho a la reparación o sustitución de la cosa no conforme y la naturaleza de la obligación del vendedor, en La modernización del Derecho de las obligaciones (Madrid, Thomson Civitas, 2006), p. 198.

${ }^{38}$ Martínez Velencoso, Luz María, La falta de conformidad en la compraventa 
Desde la perspectiva civil, hay que mencionar que la reparación no fue reconocida en el régimen de saneamiento por vicios redhibitorios de la compraventa civil. Así lo sostuvo Arturo Alessandri ${ }^{39}$ que negaba la posibilidad de reparar los vicios de la cosa, porque el legislador no lo autorizó, limitándolo a la rescisión de la venta o la rebaja del precio.

La reparación constituye una obligación de hacer que en sede compraventa pertenece al ámbito del saneamiento de la evicción (defensa del comprador en el juicio según el artículo 1840 CC.). No se conoce para las acciones edilicias de la compraventa. Sí está presente en las obligaciones de hacer ex artículo $1553 \mathrm{CC}$. y en los contratos relacionados con los servicios, como en el arrendamiento de obra que ordena hacer de nuevo la obra, en el artículo 2002 CC. Por su parte, Álvaro Vidal ${ }^{40}$ ha realizado esfuerzos para integrarla al sistema general.

Por esto, es importante destacar que en sede de consumo no existirían los límites procesales denunciados por Álvaro Vidal ${ }^{41}$ y Claudia Bahamondes $^{42}$ que producen la ineficacia de las obligaciones genéricas que imponen el cumplimiento por equivalencia, según la regla del artículo 534 CPC., que permite al deudor oponer la excepción de imposibilidad absoluta para la ejecución actual de la obra debida.

De este modo, se destaca la inclusión que hace la ley, lo que se explica por la naturaleza genérica y fungible de los bienes de consumo masivo y la idea de satisfacción de los intereses del consumidor. Por estas razones, se acomoda bien a las ventas con consumidores. Así lo sostiene Álvaro Vidal ${ }^{43}$, que siguiendo a Antonio Morales ${ }^{44}$, lo explica a partir de las ventas cuyas cosas no han sido fabricadas por el vendedor, como un modelo distinto de las ventas específicas y genéricas. En esta tercera categoría, se incorporarían los

de bienes. Análisis comparado de la Ley 23/2003, de 10 de julio, de Garantías en la Venta de Bienes de Consumo (Barcelona, Bosch, 2007), p. 135.

${ }^{39}$ Sin perjuicio de la voluntad de las partes, en que el citado autor concede la reparación si el vendedor se obligó a ella. Ahora bien, niega el ejercicio de la acción edilicia cuando existe un pacto para reparar la cosa, en Alessandri Rodríguez, Arturo, De la compraventa y de la promesa de compraventa (2a edición, Santiago, Editorial Jurídica de Chile, 2003), II,1, p. 223.

${ }^{40}$ Vidal Olivares, A., La pretensión, cit. (n. 8), p. 529.

${ }^{41}$ Ibíd., p. 520.

${ }^{42}$ Bahamondes Oyarzún, Claudia, Concurrencia de la indemnización de perjuicios de daños y la pretensión de cumplimiento especifico frente al incumplimiento, en DE LA MAza, Íñigo (coordinador), Cuadernos de Análisis Jurídico, VII: Incumplimiento contractual. Nuevas perspectivas (Santiago, Universidad Diego Portales, 2011), pp. 252256.

${ }^{43}$ Vidal Olivares, A., El incumplimiento, cit. (n. 8), pp. 530-531.

${ }^{44}$ Morales Moreno, A. M., El derecho a la reparación, cit. (n. 37), p. 194. 
remedios propios del contrato de obra (reparación y sustitución), de modo que sería posible asimilar las cualidades de la cosa (anomalías o vicios) como una prestación exigible a la entrega del proveedor.

\section{La sustitución.}

La sustitución o reposición consiste en la entrega al consumidor de otro producto que sea conforme con el contrato y la recuperación por el vendedor del producto que inicialmente esté le entregara ${ }^{45}$. Supone la obligación del vendedor de cambiar el objeto defectuoso por uno de idénticas características pero que esté conforme con la pretensión del consumidor.

La reposición como la designa nuestra ley o sustitución es una forma de cumplimiento, que favorece la conservación del contrato, que como lo señala Antonio Morales ${ }^{46}$ rompe la exacta correspondencia entre pretensión de cumplimiento del acreedor y el deber de prestación del deudor.

Jurídicamente la sustitución es una forma de ejecución forzosa in natura que está presente en las obligaciones de hacer. Asimismo, es un remedio típico de las ventas de género.

Para las ventas con consumidores constituye un derecho irrenunciable reconocido al consumidor en los artículos 19 y 20 LPDC.

Nuestra ley habla de reposición, pero se ha preferido designarla como sustitución. Al igual que la reparación se configura como una obligación de resultado que está ajena al saneamiento clásico de las compraventas civiles ${ }^{47}$.

Por último, cabe señalar que al igual que la reparación, este derecho nacería de las obligaciones de dar genéricas y de las de hacer ex artículo 1553 CC. y de la construcción de obra del artículo 2002 CC., que no se encuentra enunciado para las ventas específicas o de cuerpo cierto ${ }^{48}$.

\section{La rebaja del precio.}

La rebaja del precio es un remedio clásico proveniente de las acciones edilicias que también recibe el nombre de quanti minoris o estimatoria, y

${ }^{45}$ Marín López, Manuel Jesús, Las garantías en la venta de bienes de consumo en la Unión Europea. La Directiva 1999/44/CE y su incorporación en los Estados Miembros (Madrid, Instituto Nacional del Consumo, 2004), p. 165.

${ }^{46}$ Morales Moreno, A. M., cit. (n. 37), p. 191.

${ }^{47}$ Las cualidades de la cosa forman parte del contenido obligacional del vendedor, pero en la venta específica no son exigibles. El comprador no puede exigir al deudor que subsane los defectos de la cosa, en Morales Moreno, A. M., cit. (n. 37), pp. 192-193.

${ }^{48}$ Represa Polo, María Patricia, Los derechos del consumidor ante el incumplimiento de la obligación de conformidad, en Díaz Alabart, Silvia (coordinadora), Garantía en la venta de bienes de consumo (Madrid, Edisofer, 2006), p. 137. 
como su nombre lo señala, se trata de reducir el precio o devolver lo pagado en exceso por la existencia de un vicio en la cosa.

La acción estimatoria es un remedio propio de la compraventa de especie o cuerpo cierto fundado en el sinalagma del contrato bilateral. Es una forma de restablecer las equivalencias entre el valor de las prestaciones (cosa y precio) que impone unilateralmente al vendedor una modificación del contrato ${ }^{49}$. Como lo señala Antonio Morales ${ }^{50}$, su ejercicio supone una disconformidad que hace perder su valor desde la compra hasta entrega. $Y$ pese a la estrechez de su ámbito de aplicación en nuestro medio nacional, Pamela Prado ${ }^{51}$ propugna, con razón, una vocación de generalidad en el sistema de responsabilidad civil.

Este derecho está consagrado para las anomalías de cantidad del artículo 19 LPDC. No se indica para los problemas de calidad, falta de especificaciones y vinculación publicitaria. Como este remedio no está consagrado en el artículo 20 LPDC. podría pensarse que no procedería para los vicios de calidad, falta de especificaciones y vinculación publicitaria (artículo 20).

Hernán Corral ${ }^{52}$ sugiere que habría una jerarquía de la sustitución frente a los demás derechos. Primaría la reposición o sustitución, y si no es posible, el consumidor podría optar por la bonificación o la reducción del precio. De ser así, la rebaja se aplicaría igual que en los sistemas europeos, cuando la anomalía no podría ser subsanable o si la ejecución produce retrasos excesivos o es previsible que no pueda cumplir de forma oportuna ${ }^{53}$. Sin embargo, parece que nuestra ley sí permitiría optar, sin subordinación, de forma libre. El consumidor puede acudir a este derecho como primera opción.

Con todo, hay que señalar que los consumidores no eligen este remedio por las características propias de las cosas fabricadas en masa. Estos bienes, por su naturaleza, son fácilmente reemplazables. Es mejor acudir a la sustitución, y si ella no es posible (lo que es poco probable) se preferirá la rebaja del precio.

\section{La resolución.}

La devolución de la cantidad pagada, como lo denomina la ley, consiste

${ }^{49}$ De Verda y Beamonte, José Ramón, Saneamiento por vicios ocultos. Las acciones edilicias (2a edición, Navarra, Aranzadi - Thomson Reuters, 2009), p. 252.

${ }^{50}$ Morales Moreno, A. M., Compraventa, cit. (n. 5), p. 198.

${ }^{51}$ Prado López, Pamela, La rebaja del precio como un remedio contractual en el Derecho chileno: Una aproximación, en en ElORRIAGA, Fabián (coordinador), Estudios de Derecho Civil VII (Santiago, Thomson Reuters - AbeledoPerrot, 2012), pp. 369-383.

${ }^{52}$ Corral Talciani, H., Responsabilidad por incumplimiento, cit. (n. 33), pp. 98-99.

${ }^{53}$ Morales Moreno, A. M., cit. (n. 3), pp. 131-132. 
en la facultad de resolver el contrato. Daniel Peñailillo ${ }^{54}$ critica, con razón, la nomenclatura empleada del artículo 20 LPDC., al confundir sus efectos (la restitución de una de las prestaciones) con la institución que regula.

La resolución del contrato supone el quiebre del vínculo contractual por el incumplimiento del vendedor. Deja sin efecto la venta y se producen (en caso de existir) las restituciones mutuas reguladas en materia de obligaciones condicionales. Además supone una liberación del acreedor que, en la compraventa, se traduce en el no pago del precio.

La resolución es un mecanismo eficaz para el acreedor. Tal como lo sugieren Enrique Barros ${ }^{55}$ y Daniel Peñailillo ${ }^{56}$, se evitan riesgos mayores producto del incumplimiento y permite al cumplidor obtener lo querido por otra vía más adecuada. Álvaro Vidal ${ }^{57}$ estima que el acreedor, por regla general emplea esta opción cuando no resulta útil la prestación de corrección y desea celebrar un negocio de reemplazo con un tercero.

Con razón, Luis Díez-Picazo ${ }^{58}$ expresa que la resolución permite al acreedor obtener la satisfacción de su interés, ya no del deudor incumplidor, sino del mercado pensando en las operaciones de reemplazo.

En el ámbito del consumo opera la misma lógica. El consumidor no quiere seguir vinculado con el proveedor y prefiere optar por la resolución para buscar otras alternativas para adquirir el bien fabricado en masa.

El artículo 20 LPDC. menciona la devolución de la cantidad pagada. Por su parte, el artículo 19 no la contempla. Podría pensarse que la facultad de optar por la bonificación sería una modalidad de la resolución. Sin embargo, parece que se adecúa mejor a la subsanación, pero que excede los marcos del género de la cosa vendida.

Además, conviene señalar que la resolución es un remedio que prescinde de la imputabilidad del deudor. Y aun cuando se está consolidando esta idea en sede civil, me parece que en las ventas con consumidores de la LPDC. tampoco se requeriría de culpa (o dolo).

En nuestra legislación, las ventas civiles y entre comerciantes han con-

${ }^{54}$ Peñailillo Arévalo, Daniel, Obligaciones. Teoría general y clasificaciones. La resolución por incumplimiento (Santiago, Editorial Jurídica de Chile, 2003), p. $431 \mathrm{n}$. 789.

${ }^{55}$ Barros Bourie, E., Finalidad y alcance, cit. (n. 7), p. 420.

${ }^{56}$ Peñailillo Arévalo, D., cit. (n. 52), p. 395.

${ }^{57}$ Que además advierte que en nuestra doctrina la facultad resolutoria se ha examinado respecto de los incumplimientos totales, pretiriendo su aplicación para los imperfectos, en Vidal Olivares, A., La noción de incumplimiento, cit. (n. 16), p. 224. En este sentido, Mejías Alonzo, C., El incumplimiento contractual, cit. (n. 13), pp. 459 ss.

${ }^{58}$ Díez-Picazo y Ponce de León, L., Fundamentos de derecho, cit. (n. 14), p. 817. 
templado, ya sea por vía legal o por los desarrollos de la doctrina, la idea de calificar el incumplimiento como resolutorio, para prevalecer el contrato.

El único que era partidario de resolver frente a cualquier clase de inejecución fue Arturo Alessandri al sostener que: " $[\mathrm{P}]$ or último la violación de cualquiera otra de las obligaciones que el contrato de venta que imponga al vendedor autoriza al comprador para pedir la resolución o el cumplimiento del contrato, a virtud de lo dispuesto en el artículo 1489 CC." 59.

De este modo, es posible señalar que desde antaño se ha calificado el incumplimiento. Así por ejemplo Luis Claro ${ }^{60} \mathrm{y}$ con posterioridad Fernando Fueyo ${ }^{61}$ sustentaron la tesis de la relatividad del incumplimiento.

En la actualidad, se habla de "incumplimiento resolutorio" o de cierta entidad que permite el ejercicio de este remedio. En este sentido, Álvaro Vidal $^{62}$, Carlos Pizarro ${ }^{63}$ y Claudia Mejías ${ }^{64}$ lo tipifican como un incumplimiento grave o esencial, en base a una serie de disposiciones del Código Civil que van más allá de la buena fe y la equidad natural. Enrique Barros ${ }^{65}$ lo llama "incumplimiento significativo".

En materia de consumo, no se ha considerado que el incumplimiento sea resolutorio de forma expresa. Por integración con las normas de Derecho común, se considera adecuado que se califique el incumplimiento esencial o significativo.

${ }^{59}$ Incluso agrega que el ejercicio de estas acciones requiere: 1) que el vendedor esté constituido en mora de entregar; 2) que esa mora sea imputable a su hecho o culpa; y 3 ) que el comprador se allane a pagar el precio o se la haya señalado un plazo para hacerlo, en Alessandri Rodríguez, A., cit. (n. 41), p. 782.

${ }^{60}$ Que en base a la equidad descarta la procedencia de la resolución para el incumplimiento relativo e insignificante, en Claro Solar, Luis, Explicaciones de Derecho Civil chileno y comparado, XI: De las obligaciones, 2 (Santiago, Nascimento, 1937), p. 191.

${ }^{61}$ Que concluye que no cualquier clase de incumplimiento permite la resolución, sino que uno "objetivo" que goza de trascendencia, importancia, entidad de lo incumplido y para ello acude a la "Convención de Viena", en Fueyo LANERI, F., cit. (n. 23), pp. 312-314.

${ }^{62}$ La norma más idónea para arribar tal conclusión es el artículo 1926 CC. que permite unir el propósito práctico y los incumplimientos resolutorios con la interpretación de la regla contractual, y también los artículos 1590 y 1858 que exige importancia del vicio, y el artículo 1868 que otorga sólo la rebaja del precio junto con el artículo 1928, en Vidal Olivares, A., El incumplimiento, cit. (n. 8), pp. 533-534; Vidal Olivares, A., La noción de incumplimiento, cit. (n. 8), p. 236.

${ }^{63}$ Pizarro Wilson, C., La culpa, cit. (n. 9), p. 400.

${ }^{64}$ MejÍAs Alonzo, C., El incumplimiento resolutorio en la jurisprudencia nacional, cit. (n. 13), p. 752; y en Mejías Alonzo, C., El incumplimiento resolutorio en el Código Civil, cit. (n. 13), pp. 188-212.

${ }^{65}$ Barros Bourie, E., Finalidad y alcance, cit. (n. 7), p. 422. 


\section{La indemnización de perjuicios.}

La indemnización de perjuicios es un remedio que nace por los vicios de las cosas que causan daños. Y a diferencia de los demás derechos de la garantía legal requiere imputabilidad de parte del deudor ${ }^{66}$.

La ley lo consagra sólo en el artículo 20 LPDC., de hecho es el primero que se señala, pero no contiene una regulación.

Como se dijo, el artículo 19 LPDC. no la contempla expresamente. Por esta razón, Álvaro $\mathrm{Vidal}^{67}{ }^{6}$ estimó que bajo este el supuesto el acreedor se ve privado de este derecho. Por este motivo, quizás la mayoría de las demandas invoquen el artículo 20 y no el artículo 19.

De todas formas, si hay perjuicios sería posible direccionar el conflicto hacia las normas que regulan los derechos básicos del consumidor. En concreto al artículo 3 letra e) que reconoce el derecho irrenunciable "a la reparación e indemnización adecuada y oportuna de todos los daños materiales y morales en caso de incumplimiento de cualquiera de las obligaciones contraídas por el proveedor". Entonces, el consumidor siempre puede optar por la indemnización de perjuicios aún bajo la regla del artículo 19, porque forma parte del sistema de responsabilidad contractual del consumidor.

Si se lo que quiere ver como un derecho irrenunciable comprendería los daños patrimoniales y morales que siempre deben ser declarados por el Juez.

Tal como se ha venido aclarando en el Derecho común, la pretensión indemnizatoria cumple una función que va más allá del pago por equivalencia, es un remedio autónomo que comprende no sólo la prestación debida, sino que también los daños distintos al objeto del contrato o en la persona del acreedor ${ }^{68}$.

En contraste, recién la doctrina civil ha despejado la dependencia de la indemnización frente al cumplimiento o resolución. Así, Enrique Barros ${ }^{69}$, Carlos Pizarro ${ }^{70}$, Álvaro Vidal ${ }^{71}$, y en un artículo dedicado a este tema en concreto Patricia López ${ }^{72}$ postula que debe reinterpretarse la expresión "con" del artículo 1489 CC. en el siguiente sentido: "o la indemnización de perjuicios que estime procedente o además de la indemnización de per-

${ }^{66}$ Por todos: Pizarro Wilson, C., Hacia un sistema, cit. (n. 9), p. 400.

${ }^{67}$ Vidal Olivares, A., El incumplimiento, cit. (n. 8), p. 528.

${ }^{68}$ Pizarro Wilson, C., La responsabilidad contractual, cit. (n. 9), p. 301.

${ }^{69}$ Barros Bourie, E., Finalidady alcance, cit. (n. 7), p. 414.

${ }^{70}$ Pizarro Wilson, C., La responsabilidad contractual, cit. (n. 9), p. 311.

${ }^{71}$ Vidal Olivares, A., La indemnización de daños, cit. (n. 8), pp. 763 ss.

${ }^{72}$ López DíAz, Patricia, La indemnización compensatoria por incumplimiento de los contratos bilaterales como remedio autónomo en el derecho civil chileno, en Revista Chilena de Derecho Privado, 15 (Santiago, 2010), p. 86. 
juicios pertinente”, para reafirmar su autonomía frente a los otros remedios disponibles para el acreedor en los contratos bilaterales.

Incluso algunas sentencias recientes defienden la autonomía de la indemnización, como en "Zorín S.A. con Compañía Siderúrgica Huachipato”73 a propósito de la calidad de ciertos rodillos de aceros, en que la Corte Suprema dio lugar sólo a la indemnización de perjuicios, sin resolver o hacer cumplir el contrato de compraventa.

Con anterioridad, se creía que la indemnización de perjuicios era accesoria o dependiente del cumplimiento o la resolución del artículo 1489 CC, al menos para las obligaciones de dar no dinerarias. Nuestra doctrina clásica así lo consideraba. En este sentido, Luis Claro Solar ${ }^{74}$, Arturo Alessandri ${ }^{75}$, Fernando Fueyo ${ }^{76}$, Ramón Meza ${ }^{77}$, René Abeliuk ${ }^{78}$, Hernán Troncoso ${ }^{79}$, entre otros.

En suma, en materia de garantía legal el consumidor contaría con una serie de acciones más o menos articuladas, que hacen una escisión según si las anomalías son de cantidad y todas las demás. Con todo, se contemplan cinco derechos irrenunciables a favor del consumidor, la reparación, sustitución, rebaja del precio, resolución e indemnización de perjuicios. Ahora, corresponde examinar cómo operan.

${ }^{73}$ Rol N ${ }^{\circ} 3325-2012$, CL/JUR/2412/2012, Santiago: Corte Suprema, sentencia de 31 de octubre de 2012. El considerando $9^{\circ}$ de la sentencia de reemplazo así lo establece: "[U]na vez establecido que efectivamente ha existido un incumplimiento del contrato, corresponde determinar si la actora ha podido ejercer la acción indemnizatoria, como lo ha hecho, prescindiendo de lo que disponen los artículos 1489 y 1826 del Código Civil, que parecen indicar que tal acción no es autónoma, sino que debe siempre ir acompañada sea de la petición de resolución contractual o bien de la exigencia de cumplimiento del contrato. Como ya lo ha resuelto esta Corte en otras oportunidades, y siguiendo una moderna tendencia doctrinal ( $\left.\mathrm{Rol} \mathrm{N}^{\circ} 3.341-012\right)$, se estima que, en este caso, la demandante ha podido plantear su demanda de responsabilidad civil contractual, sin asociarla a la resolución del contrato, pues, la entrega material de los rodillos está cumplida y parte de ellos fueron cortados".

${ }^{74}$ Que la concebía como un derecho secundario del acreedor, Claro Solar, L., cit. (n. 60), p. 723.

${ }^{75}$ Alessandri Rodríguez, A., cit. (n. 39) p. 779.

${ }^{76}$ FueYo LANERI, F., cit. (n. 23), p. 353, la caracterizaba como subsidiaria frente a las acciones de cumplimiento, primero por naturaleza y luego en equivalencia, y luego respecto de la resolución.

${ }^{77}$ Meza Barros, Ramón, Manual de Derecho Civil. De las fuentes de las obligaciones (9a edición, Santiago, Editorial Jurídica de Chile, 2007), p. 63.

${ }^{78}$ Abeliuk Manasevich, R., cit. (n. 23), p. 411.

${ }^{79}$ Troncoso Larronde, Hernán, De las obligaciones ( $5^{a}$ edición, Santiago, LexisNexis, 2007), p. 141. 


\section{LA ARTICULACIÓN DE LOS REMEDiOS DE LA GARANTÍA LEGAL}

El estudio de la compatibilidad o incompatibilidad de acciones tiene una serie de consecuencias prácticas. Siguiendo a Enrique Barros ${ }^{80}$, habría que examinar una serie de razones lógicas relacionadas con la congruencia, el principio de enriquecimiento sin causa, o la buena fe contractual. Desde el punto de vista procesal habría que atender a la preclusión de una acción o excepción en el proceso. Por razones de tiempo, sólo se examinarán la articulación de los derechos de la garantía legal desde el punto de vista civil, pese a las implicancias procesales.

Dicho esto, conviene señalar que la articulación de remedios de la garantía legal obedece a una fórmula dual.

La primera de ellas, podría denominarse alternativa entre las medidas de cumplimiento (reparación y la sustitución) y las que dejan sin efecto el contrato (rebaja del precio y la resolución de contrato). Es decir, el consumidor puede optar de manera libre por cualquiera de ella, la que mejor satisfaga sus intereses.

La segunda, acumulativa, que supone la unión de cualquiera de los derechos enunciados con anterioridad con la indemnización de perjuicios.

Esto será lo que examinará a continuación.

\section{La compatibilidad alternativa.}

La garantía legal del consumo recoge un sistema de responsabilidad por incumplimiento de obligaciones de dar genéricas, por lo que habría que dar lugar a la opción entre sus acciones.

En sede civil, cuando se ha incumplido la obligación contractual debe admitirse la opción. En la actualidad, se defiende la libertad de la opción, sin que exista una primacía por el cumplimiento.

Por este motivo, Carlos Pizarro $^{81}$, sugiere que la primacía de la ejecución en naturaleza no podría fundarse en el principio de la fuerza obligatoria del contrato, porque resultaría paradójico que el deudor pueda escudarse en ella para hacer pervivir el contrato. Si se pensara así, se convertiría en un obstáculo al reconocimiento de la opción.

\footnotetext{
${ }^{80}$ Barros Bourie, E., Finalidad y alcance, cit. (n. 7), p. 408. Sobre las relaciones del concurso en el ámbito civil, Barros Bourie, E., La diferencia, cit. (n. 7), pp. 733735.

${ }^{81}$ Pizarro Wilson, C., La responsabilidad contractual, cit. (n. 9), p. 309. La misma idea puede verse en sus reflexiones sobre el pacto comisorio calificado, Pizarro Wilson, C., Cláusulas resolutorias, cit. (n. 7), pp.245-258.
} 
Desde otra perspectiva, Álvaro Vidal ${ }^{82}$ cree que en las obligaciones genéricas de dar no hay una norma expresa que se refiera a la opción, pero ella fluye del régimen de acciones, lo que constituye una diferencia con las específicas, en que se renuncia a la posibilidad de cumplir con la obligación, y sólo cabrían las acciones edilicias, que dicho sea de paso, también contemplarían la opción, al menos, cuando los vicios son de gravedad.

Así las cosas, el sistema de las ventas de consumo es de libre elección, lo que se traduce en que el consumidor podrá optar por cualquiera de los mecanismos tuitivos, sin que exista jerarquía entre ellos.

En las ventas de consumo, no corresponde hacer la distinción entre los derechos primarios y los secundarios. Así lo establece el artículo 20 LPDC. cuando reconoce que "el consumidor podrá optar", sin imponer ningún condicionamiento. Idea, que al parecer también estaría consagrada en el 19 LPDC., pese a su redacción "en su defecto".

Con todo, una vez escogida la opción el consumidor no puede retractarse. Por lo mismo, la libertad de este sujeto, se encuentra en la facultad de elegir el remedio, pero no puede modificarse la decisión exigible al proveedor o demandada en sede judicial, esto por congruencia procesal. Quizás en sede extrajudicial, podría ocurrir que el proveedor le ofrezca otra alternativa y con eso, se modifique la opción, la que en todo caso debe ser siempre libre de parte del consumidor, sin que el proveedor pueda imponer alguna.

Lo anterior, permite generar un equilibrio en las posiciones de las partes, al evitar el perjuicio al proveedor si ya dio inicio al mecanismo resarcitorio. Por este motivo, no está demás que señalar que el proveedor no tiene (o no debiera tener) ninguna injerencia en la elección del consumidor. Tampoco el proveedor puede rechazar la opción.

\section{La compatibilidad acumulativa.}

Entonces, la primera fórmula muestra una compatibilidad alternativa que significa que los derechos del consumidor son de ejercicio único, en el sentido que sólo puede optar por uno de ellos excluyendo los demás. Esta herramienta no considera la indemnización de perjuicios. Por esto, al integrarla se añade la idea de "compatibilidad acumulativa".

La reparación, la sustitución, la rebaja del precio y la resolución serían acumulables con la indemnización de perjuicios. Cualquiera sea la norma que se invoque, el artículo 19 ó 20 LPDC., la indemnización siempre debería acumularse a las demás pretensiones [artículo 3 letra e)].

${ }^{82}$ Se excluye la opción para las obligaciones de dar específicas por el artículo 1672 CC. que contiene un límite al cumplimiento específico, que es el remedio primario, en Vidal Olivares, A., La pretensión, cit. (n. 8), p. 524. 
Incluso más allá, en el ámbito civil Álvaro Vidal ${ }^{83}$ considera que el acreedor tiene la opción de ejercer la indemnización de perjuicios de manera exclusiva (en cuyo se piden los daños intrínsecos y extrínsecos) o bien de forma complementaria, caso en el cual se limitaría el monto indemnizatorio a los daños extrínsecos (artículo 1558 CC.). Argumento que rechazaría Patricia Lópe $^{84}{ }^{84}$ cuando defiende la autonomía plena de este derecho.

Pensado en una regla proteccionista para el consumidor, debería permitirse la noción más favorable a sus intereses.

En suma, la garantía legal contiene un sistema legal de remedios traducido en una compatibilidad alternativa y acumulativa que favorece al consumidor.

\section{CONCLUSIONES}

$1^{\circ}$ El cumplimiento defectuoso de la obligación de entrega por parte del proveedor tiene una serie de consecuencias jurídicas, que se manifiestan en derechos irrenunciables, remedios o acciones a favor del consumidor. Se trata de una protección contractual que da derecho a optar por las medidas de cumplimiento o de ruptura del vínculo jurídico, acompañado de una indemnización de perjuicios.

$2^{\circ}$ La reparación gratuita de la cosa es una medida eficaz para los consumidores. Su ámbito de aplicación son las anomalías de calidad, las faltas de especificaciones y la vinculación publicitaria. No se encuentra recogida de forma expresa para los vicios de cantidad del artículo 19.

$3^{\circ} \mathrm{La}$ sustitución es una medida de cumplimiento dispuesta para todas las anomalías o faltas de conformidad de la cosa, porque está contemplada en los artículos 19 y 20 LPDC.

$4^{\circ} \mathrm{La}$ rebaja del precio es una medida propia del régimen de saneamiento de los vicios redhibitorios del derecho codificado, que ha sido traspasado a las ventas con consumidores.

$5^{\circ}$ La resolución del contrato, o como lo denomina la devolución del precio ley implica dejar sin efecto las obligaciones entre las partes de la relación de consumo. El consumidor escogerá este remedio cuando pierde

${ }^{83}$ Vidal Olivares, A., El incumplimiento, cit. (n. 8), p. 539 n. 115.

${ }^{84}$ López DíAz, P., cit. (n. 72), p. 72. Reafirma esta idea cuando explica los argumentos a favor de su tesis. En su concepto, la autonomía de la indemnización de perjuicios supone una renuncia al cumplimiento forzado o la resolución del contrato, lo que se contrapone con la compatibilidad de los remedios de la garantía legal. En realidad, el consumidor no tiene porqué renunciar, todos son compatibles. Quizás, detrás de ello se manifiesta la idea anglosajona de la indemnización de perjuicios que no comprende la pretensión de cumplimiento específico. 
la confianza en el proveedor, ya que no quiere seguir ligado a él, y celebra operaciones de reemplazo

$6^{\circ} \mathrm{La}$ indemnización de perjuicios es un remedio contemplado para la disconformidad de las especificaciones de la cosa, la calidad y la integración publicitaria del artículo 20. No se contempla en el artículo 19, pero igualmente sería procedente conforme lo prescribe el artículo 3 letra e), que le otorga el carácter de irrenunciable. Esta pretensión es autónoma en sede de consumidores, lo que significa que sería posible acudir sólo a ella, sin necesidad de solicitar otro remedio.

$7^{\circ} \mathrm{El}$ sistema de la garantía legal es de libre elección. El consumidor puede optar por la reparación, la sustitución, la rebaja del precio y la resolución del contrato una sola vez y desde el comienzo, por el derecho que mejor se aviene con su interés. No puede modificar su decisión. Esto genera equilibrio en el contrato.

$8^{\circ}$ Junto con lo anterior, el sistema se presenta una concurrencia con la indemnización de perjuicios, al ser compatible con todos los demás remedios que emanan de la garantía legal de consumo.

\section{BIBLIOGRAFÍA}

Abeliuk Manasevich, René, Las obligaciones ( 5 a edición actualizada, Santiago, Editorial Jurídica de Chile, 2010).

AlessANDRI RodrígueZ, Arturo, De la compraventa y de la promesa de compraventa (2a edición, Santiago, Editorial Jurídica de Chile, 2003), II,1.

Bahamondes Oyarzún, Claudia, Concurrencia de la indemnización deperjuicios de daños y la pretensión de cumplimiento especifico frente al incumplimiento, en DE LA MAZA, Íñigo (coordinador), Cuadernos de Análisis Jurídico, VII: Incumplimiento contractual. Nuevas perspectivas. (Santiago, Ediciones Universidad Diego Portales, 2011).

BARAONA GONZÁLEZ, Jorge, Responsabilidad contractual y factores de imputación de daños: apuntes para una relectura en clave objetiva, en Revista Chilena de Derecho, 24 (Santiago, 1996) 1.

Barrientos Camus, Francisca, Comentario al artículo 19 y comentario al artículo 20, en De la Maza, Iñigo - Pizarro, Carlos (directores) - Barrientos, Francisca (coordinadora), La protección de los derechos de los consumidores. Comentarios a la Ley de protección a los derechos de los consumidores (Santiago, Thomson Reuters, 2013).

BARros BourIE, Enrique, Finalidad y alcance de las acciones y remedios contractuales, en GuZmán BRito, Alejandro (editor científico), Estudios de Derecho Civil III(Santiago, LegalPublishing, 2008).

BArros Bourie, Enrique, La diferencia entre "estar obligado" y "ser responsable" en el derecho de los contratos, en CORRAL, Hernán - RodRíguEZ, María Sara (coordinadores), Estudios de Derecho Civil II (Santiago, LexisNexis, 2006).

Barros Bourie, Enrique, El contrato y el hecho que causa daño como antecedentes de la responsabilidad, en Pizarro Wilson, Carlos (editor), Estudios de Derecho Civil IV (Santiago, Editorial LegalPublishing, 2009). 
BetTi, Emilio, Teoría general de las obligaciones (traducción de José Luis de los Mozos, Madrid, Editorial Revista de Derecho Privado, 1969).

Brantt Zumarán, María Graciela, El caso fortuito y su incidencia en el Derecho de la responsabilidad contractual. Concepto y función del caso fortuito en el Código Civil chileno (Santiago, LegalPublishing, 2010).

Brantt Zumarán, María Graciela, El caso fortuito: concepto y función como límite de la responsabilidad contractual, en DE LA MAZA, Ínigo (coordinador), Cuadernos de Análisis Jurídico, VII: Incumplimiento contractual. Nuevas perspectivas (Santiago, Universidad Diego Portales, 2011).

Brantt Zumarán, María Graciela, La prueba del cumplimiento imperfecto en las obligaciones de medios y de resultado, en ElorRIAGA, Fabián (coordinador), Estudios de Derecho Civil VII (Santiago, Thomson Reuters - AbeledoPerrot, 2012).

Castilla Barea, Margarita, La determinación de la "falta de conformidad" del bien con el contrato a tenor del art. 2 de la Directiva 1999/44/C.E., del Parlamento Europeo y del Consejo, de 25 de mayo, sobre determinados aspectos de la venta y las garantías de los bienes de consumo, en Anuario de la Facultad de Derecho de la Universidad de Extremadura, 21 (2003).

Claro Solar, Luis, Explicaciones de Derecho Civil chileno y comparado, XI: De las obligaciones, 2. (Santiago, Nascimento, 1937).

CoRral Talciani, Hernán, La responsabilidad por incumplimiento y por productos peligrosos en la ley de protección de los derechos de los consumidores, en BARAONA, Jorge - LAGos, Osvaldo Cuadernos de extensión Jurídica, XII: La protección de los derechos de los consumidores en Chile. Aspectos sustantivos y procesales luego de la reforma contenida en la Ley $N^{\circ} 19.955$ de 2004 (Santiago, Universidad de los Andes, 2006).

Corral Talciani, Hernán, Ley de protección al consumidor y responsabilidad civil, en Corral, Hernán (editor), Cuadernos de Extensión Jurídica, III: Derecho del consumo $y$ protección al consumidor. Estudios sobre la Ley $N^{\circ} 19.496$ y las principales tendencias extranjeras (Santiago, Universidad de los Andes, 1999).

De Castro y Bravo, Federico, El negocio jurídico (Madrid, Civitas, 1985).

De la MAZa GAZMURI, Ínigo, El concurso entre el error con trascendencia anulatoria y el incumplimiento resolutorio, en DE LA MAZA, Íñigo (coordinador), Cuadernos de Análisis Jurídico, VII: Incumplimiento contractual. Nuevas perspectivas (Santiago, Ediciones Universidad Diego Portales, 2011).

De la Maza Gazmuri, Íñigo, El régimen de los cumplimientos defectuosos en la compraventa, en Revista Chilena de Derecho, 39 (Santiago, 2011) 3.

De Verda y Beamonte, José Ramón, Saneamiento por vicios ocultos. Las acciones edilicias. (2a edición, Navarra, Aranzadi - Thomson Reuters, 2009).

Díez-Picazo y Ponce de León, Luis, La compraventa internacional de mercaderías. Comentario de la Convención de Viena (Madrid, Civitas, 1997).

Díez-Picazo y Ponce de León, Luis, Reforma de los Códigos y Derecho Europeo, en Anuario de Derecho Civil, 56 (Madrid, 2003).

Fenoy Picón, Nieves, Elsistema deprotección del comprador (Madrid, Centro de Estudios registrales, 2006).

Fenoy Picón, Nieves, Falta de conformidad e incumplimiento en la compraventa: evolución del ordenamiento español (Madrid, Centro de Estudios Registrales, 1996).

Fueyo LANeri, Fernando, Cumplimiento e incumplimiento de las obligaciones (Santiago, Editorial Jurídica de Chile, 2004).

López DíAz, Patricia, La indemnización compensatoria por incumplimiento de los contratos 
bilaterales como remedio autónomo en el derecho civil chileno, en Revista Chilena de Derecho Privado, 15 (Santiago, 2010).

Marín López, Manuel Jesús, Las garantías en la venta de bienes de consumo en la Unión Europea.La Directiva 1999/44/CE y su incorporación en los Estados Miembros (Madrid, Instituto Nacional del Consumo, 2004).

Martín Aresti, Pilar, Las garantías de los productos de consumo (Navarra, Editorial Aranzadi - Thomson Reuters, 2010).

Martínez Velencoso, Luz María, La falta de conformidad en la compraventa de bienes. Análisis comparado de la Ley 23/2003, de 10 de julio, de Garantías en la Venta de Bienes de Consumo (Barcelona, Bosch, 2007).

Mejías Alonzo, Claudia, El incumplimiento contractual y sus modalidades, en Varas, Juan Andrés - Turner, Susan (coordinadores), Estudios de Derecho Civil II (Santiago, LexisNexis, 2005).

Mejías Alonzo, Claudia, El incumplimiento resolutorio en el Código Civil (Santiago, AbeledoPerrot - LegalPublishing, 2011).

Mejías Alonzo, Claudia, El incumplimiento resolutorio en la jurisprudencia nacional, en Figueroa Yáñez, Gonzalo (editor), Estudios de Derecho Civil VI (Santiago, AbeledoPerrot - LegalPublishing, 2011).

Meza Barros, Ramón, Manual de Derecho civil. De las fuentes de las obligaciones (9a edición, Santiago, Editorial Jurídica de Chile, 2007).

Morales Moreno, Antonio Manuel, Adaptación del Código Civil al derecho europeo: la compraventa, en La modernización del Derecho de las obligaciones (Madrid, Thomson Civitas, 2006).

Morales Moreno, Antonio Manuel, El "propósito práctico" y la idea de negocio jurídico en Federico De Castro, en La modernización del Derecho de las obligaciones (Madrid, Thomson Civitas, 2006).

Morales Moreno, Antonio Manuel, El derecho a la reparación o sustitución de la cosa no conforme y la naturaleza de la obligación del vendedor, en La modernización del Derecho de las obligaciones (Madrid, Thomson Civitas, 2006).

Morales Moreno, Antonio Manuel, Evolución del concepto de obligación en el derecho español, en La modernización del Derecho de las obligaciones (Madrid, Thomson Civitas, 2006).

Morales Moreno, Antonio Manuel, La compraventa internacional de mercaderías. Comentario de la Convención de Viena (Madrid, Thomson Civitas, 1997).

Morales Moreno, Antonio Manuel, La conformidad de la cosa vendida según la Directiva 1999/44/CE, en La modernización del Derecho de las obligaciones (Navarra, Editorial Thomson Civitas, 2006).

Nasser Olea, Marcelo, Comentario al artículo 21, en de la Maza, Iñigo - Pizarro, Carlos (directores) - BARrientos, Francisca (coordinadora), La protección de los derechos de los consumidores. Comentarios a la ley de protección a los derechos de los consumidores (Santiago, Thomson Reuters, 2013).

PANTALEÓn PrIETo, Ángel Fernando, El sistema de responsabilidad contractual (materiales para un debate), en Anuario de Derecho Civil, 44 (Madrid, 1991) 3.

Pantaleón Prieto, Ángel Fernando, Las nuevas bases de la responsabilidad contractual, en Anuario de Derecho Civil, 46 (Madrid, 1993) 4.

Peñailillo Arévalo, Daniel, Obligaciones. Teoría general y clasificaciones. La resolución por incumplimiento (Santiago, Editorial Jurídica de Chile, 2003).

Peñailillo Arévalo, Daniel, Responsabilidad contractual objetiva, en Pizarro WiL- 
son, Carlos (editor) Estudios de Derecho Civil IV (Santiago, Editorial LegalPublishing, 2009).

Pizarro Wilson, Carlos, Hacia un sistema de remedios al incumplimiento contractual, en GuZmán Brito, Alejandro (editor científico), Estudios de Derecho Civil III (Santiago, LegalPublishing, 2008).

Pizarro Wilson, Carlos, La culpa como elemento constitutivo del incumplimiento en las obligaciones de medio o de diligencia, en Revista de Derecho de la Pontificia Universidad Católica de Valparaíso, 31 (2008).

Pizarro Wilson, Carlos, La responsabilidad contractual en Derecho chileno, en Pizarro Wilson, Carlos - Vidal Olivares, Álvaro Incumplimiento contractual, resolución e indemnización de daños. (Bogotá, Universidad del Rosario, 2010).

Prado López, Pamela, La rebaja del precio como un remedio contractual en el Derecho chileno: Una aproximación, en Elorriaga, Fabián (coordinador), Estudios de Derecho Civil VII (Santiago, Thomson Reuters - Abeledo Perrot, 2012).

Represa Polo, María Patricia, Los derechos del consumidor ante el incumplimiento de la obligación de conformidad, en Díaz Alabart, Silvia, Garantía en la venta de bienes de consumo (Madrid, Edisofer, 2006).

San Miguel Pradera, Lis Paula, Resolución del contrato por incumplimiento y modalidades de ejercicio (Madrid, Colegio de Registradores de la Propiedad y Mercantiles de España, 2006).

Troncoso Larronde, Hernán, De las obligaciones. (5a edición Santiago, LexisNexis, 2007).

Vidal Olivares, Álvaro, Cumplimiento e incumplimiento contractual en el Código Civil. Una perspectiva más realista, en Revista Chilena de Derecho, 34 (Santiago, 2009) 1.

Vidal Olivares, Álvaro, El incumplimiento contractual y los remedios de que dispone el acreedor en la compraventa internacional, en Revista Chilena de Derecho, 33 (Santiago, 2006) 3.

Vidal Olivares, Álvaro, El incumplimiento de obligaciones con objeto fungible y los remedios del acreedor afectado. Una relectura de las disposiciones del "Código Civil" sobre incumplimiento, en Guzmán Brito, Alejandro (editor científico), El Código Civil de Chile (1855-2005) (Santiago, LexisNexis, 2007).

Vidal Olivares, Álvaro, El incumplimiento resolutorio en el Código Civil, en Pizarro Wilson, Carlos (editor), Estudios de Derecho Civil IV (Santiago, LegalPublishing, 2009).

VIDAl Olivares, Álvaro, La pretensión de cumplimiento especifico y su inserción en el sistema de remedios por incumplimiento en el Código Civil, en CORRAL, Hernán - RODRÍGUEz, María Sara (coordinadores), Estudios de Derecho Civil II (Santiago, LexisNexis, 2007).

Vidal Olivares, Álvaro, La indemnización de daños y la opción del acreedor frente al incumplimiento, en Figueroa Yánez, Gonzalo (editor), Estudios de Derecho Civil VI (Santiago, Abeledo Perrot - LegalPublishing, 2011).

Vidal Olivares, Álvaro, La noción de incumplimiento esencial en el "Código Civil", en Revista de Derecho de la Pontificia Universidad Católica de Valparaiso, 32 (2009).

Vidal Olivares, Álvaro, La protección del comprador. Régimen de la "Convención de Viena" y su contraste con el Código Civil (Valparaíso, Ediciones Universitarias de Valparaíso, 2006).

Zimmermann, Reinard, El carácter europeo del Derecho inglés. Relaciones históricas entre el "civil law" y "common law", en El mismo, Estudios de Derecho privado europeo (traducción de A. Vaquer, Madrid, Civitas, 2000). 